\title{
Antecedents of Service Innovative Behavior: The Role of Spiritual Leadership and Workplace Spirituality
}

\author{
Hebah Suliman ALFARAJAT*, Okechukwu Lawrence EMEAGWALI \\ Girne American University, Faculty of Business and Economics, Girne, Cyprus, hbsat@yandex.com (*corresponding \\ author)
}

\begin{abstract}
Background: Managers in labor-intensive industries are facing challenges on how to encourage innovation, as services are mostly offered by employees and not machines. Intense competition in the service and hospitality industry calls for more innovative work behavior exhibition among employees, and the question on how enterprises can nurture innovative behavior remains unanswered. The objective of the research is to clarify the inter-relationship between spiritual leadership and workplace spirituality and how their collective effect can nurture employee service innovative behavior in the hospitality industry by drawing on relational energy theory.

Methodology: Data were obtained using a survey quantitative research method based on a convenience sampling technique from $(n=867)$ employees working in four- and five-star Jordanian hotels. A partial least squares structural equation modeling (PLS-SEM) technique was applied to assess the proposed research model and hypotheses.

Results: Findings from PLS-SEM show that spiritual leadership impacts and increases the level of workplace spirituality and service innovative behavior among employees. Workplace spirituality increases the level of service innovative behavior and mediates the relationship between spiritual leadership and service innovative behavior.

Conclusion: Spiritual leadership and workplace spirituality initiatives and practices can be beneficial for hospitality enterprises in terms of service innovative behavior. Moreover, the key point is that hospitality HR practitioners should not only focus on selecting, training, and appointing leaders with spiritual characteristics, but also on creating a spiritual work atmosphere to enable employees to exhibit service innovative behaviors. The results did not only advance our knowledge concerning the nexus and importance of spirituality in the workplace, but also validates and reveals the importance of spirituality on innovative behavior in the Arabian context.
\end{abstract}

Keywords: Behavior, Innovation, Jordan, Service, Spiritual leadership, Workplace spirituality

\section{Introduction}

The present-day business environment is characterized as having intense competition and uncertainties, which increases work pressure and anxiety among employees. Work pressure, stress, and anxiety have been associated with negative work outcomes (Abubakar, 2018; Tabor et al., 2019). Hence, the need for leaders who can motivate, share, and energize employees to deal with these problems has never been this great before (Ghaedi et al., 2020; Tabor et al., 2019). Unlike other traditional leadership traits, spiritual leadership is a value-based and spirit-centered style to leadership that stresses workers' perception of meaningful work by fulfilling their need for otherworldly survival (Fry, 2003). Many studies have linked spiritual leadership to increased workplace spirituality (Afsar et al., 2016; Fry \& Slocum, 2008). Spirituality in the workplace is distinct from spirituality in general, as it relates with individual spiritual well-being within the context of employment.

Workplace spirituality has been defined as "a framework of organizational values evidenced in the culture that promote employees' experience of transcendence through the work process, facilitating their sense of being connected to others in a way that provides feelings of complete-

Received: 12th July 2021; revised: 4th November 2021; accepted: 11 th November 2021 
ness and joy" (Giacalone \& Jurkiewicz, 2003). At work, employees are typically insecure and fearful, which is why they rely on workplaces and peers for social support and courage and identity (Jurkiewicz \& Giacalone, 2004). Specifically, workplace spirituality aims to empower workers to discover the purpose of life, develop bonds with peers, and enhance work atmosphere (Fry \& Slocum, 2008). Tentatively, spirituality in the workplace is not limited to practices such as cultural diversity, fairness, ethics, support, and development programs, but also covers facets of innovation, as individuals work in harmony, have shared goals, are encouraged to share knowledge and allowed to express their opinions.

Innovative behavior is seen as employees' response and generation of solutions to ongoing business problems (Cozzarin, 2017; Scott \& Bruce, 1994). Because of the tremendous rivalry among businesses in today's economic climate, exhibition of innovative behavior is extremely important. Basically, spiritual leadership and workplace spirituality have many beneficial effects on employees, such as high levels of life satisfaction, organizational citizenship behavior, and in-role performance (Houghton et al., 2016; Krishnakumar et al., 2015), organizational commitments (Fry \& Slocum, 2008), and group innovativeness (Ghaedi et al., 2020). Existing works on spiritual leadership are mainly focused on employee well-being and outcomes, the question as to the benefit of how spiritual leadership affects performance remains elusive as shown in a meta-analytical study (Oh \& Wang, 2020). To this end, this study aims to make pivotal contributions to spiritual leadership and workplace spirituality research streams. Since only a few studies have linked the concepts to innovative outcomes in the hospitality industry (Oh \& Wang, 2020), our work will add to the body of knowledge.

Second, by incorporating service innovative behavior, we unveil the mechanism by which spiritual leadership practices result in desired organizational outcomes. Specifically, this paper draws on the theory of relational energy (McDaniel, 2011) to investigate the relationship between spiritual leadership, workplace spirituality, and service innovative behavior. Third, although, it is acknowledged that spiritual care does not equate only to religious care (Weathers, 2018), there is almost an inseparable link between spiritual and religious practices in a Middle Eastern and Muslim context. Because most practices and teachings such as connection, peace, transcendence are drawn from the Holy Quran and Hadiths (Cruz et al., 2017). Thus, the hospitality and Arabian context of this study provides a relevant domain for additional invetsigation, as past works were mostly in advanced nations such as the US and Far East context such as China. This study expands on the Afsar et al. (2016) theoretical model of spirituality in terms of organization and leadership by adopting an innovative perspective and investigating the associations in a different contextual setting, specifically, the hospitality industry.
Similar calls for additional studies in the hospitality industry context were issued by Milliman et al. (2018).

\section{Literature review and hypotheses development}

A positive sensation and sense of enhanced resourcefulness due direct psycho-social interaction with others is known as relational energy. According to relational energy theory, some individuals appear to boost our energy, optimism, and wit, while others appear to have no effect or drain such vitality or energy. More specifically, energy emanating from colleagues can impact the work motivations of individuals as a result of 'contagious effects' (McDaniel, 2011; Owens et al., 2016). Research also found that the level of relational energy among members of a team equates to their performance (Borgatti \& Cross, 2003). Employee service innovative behavior denotes "the production or adoption of useful ideas and idea implementation and begins with problem recognition and the generation of ideas or solutions" (Scott \& Bruce, 1994, p. 581). These behaviors have been shown to boost organizational growth, agility, productivity, and competitiveness (Hu et al., 2009; Shih \& Susanto, 2016). Work behaviors are essential inputs for value creation, due to their role in how businesses innovate. Several studies have linked leadership style (Ghaedi et al., 2020; Afsar et al., 2016) and organizational culture (Kaya et al., 2020; Likoum et al., 2020) to enhanced firm innovation.

Spiritual leadership is defined as "the values, attitudes, and behaviors that one must adopt in intrinsically motivating oneself and others so that both have a positive increase in the sense of spiritual well-being through calling and membership, that is, they experience meaning in their lives, have a sense of making a difference, and feel understood and appreciated" (Fry et al., 2005, p. 836). This leadership style is tripartite where the (1) vision dimension reflects a picture of the future with implicit or explicit outcomes on why people should try to make that picture come to reality; (2) hope and faith dimension reflects the belief that the goals/mission/vision of the hiring firm can be attained; and (3) altruistic love dimension reflects a sense of completeness, harmony, and well-being achieved via selfcare, love, and appreciation by others (Fry et al., 2005; Yang et al., 2019).

The employee's experience of spirituality in the workplace is called workplace spirituality (Pawar, 2009). Workplace spirituality is comprised of three dimensions, namely: at employee level - meaningful work; at team level or group level - sense of community; and alignment to organizational values at organizational level. Workplace spirituality embodies a sensation of belongingness and employee interconnectedness. Such experiences and feelings strengthen the social bond and compassion toward others, 
which foster community and/or group harmony (Milliman et al., 2003). This sense of community encourages workers to help and exhibit good Samaritan attitudes through work support, citizenship, and innovative behaviors that align with the organization's goals and values. Spirituality supports the spirit of the employees by enhancing work meaning and employee engagement (Gotsis \& Grimani, 2017; Helmy et al., 2020).

Managers and leaders "have a responsibility for nurturing the spirit by helping their subordinates be open to their inner lives, by helping them find meaning in their work, and by strengthening a sense of community in the workplace" (Duchon \& Plowman, 2005, p. 828). Spiritual leaders are known and portrayed as having humility; research shows that such traits can foster creativity in workplaces (Wang et al., 2017). All in all, spirituality can be viewed as a facilitator and life-giving energy that encourage employees to take part in helping others as well as generation of creative work ideas. Previous findings show that spiritual leadership is an antecedent for workplace spirituality (Afsar et al., 2016). Spiritual leadership together with workplace spirituality are antecedents for greater levels of life satisfaction and in-role performance (Houghton et al., 2016; Krishnakumar et al., 2015), organizational commitment (Fry \& Slocum, 2008), and group innovativeness (Ghaedi et al., 2020). In a nutshell, spiritual leaders are able to lead with calmness and strength, show some level of mindfulness, and also maintain person-centered relationships with subordinates.

Accordingly, research noted that spirituality can foster higher levels of prosocial attitudes and behavior among individuals (Rezapouraghdam et al., 2018; Wierzbicki \& Zawadzka, 2016). Some scholars have linked spiritual leadership to higher job performance (Yang et al., 2019) and group innovativeness (Ghaedi et al., 2020). Workplace spirituality has to do with the conception of connectedness and amalgamation of self-values with those of the hiring firms; when there is a fit between these two, service innovative behavior is likely to emerge. Past findings have also linked workplace spirituality with innovative and creative outcomes (Afsar \& Badir, 2017). Building on past literature, we draw on relational energy theory to suggest that spiritual leadership and workplace spirituality can spread contagious energy that could spur innovation within the hotel context. The following hypotheses are proposed:

H1: Spiritual leadership has a positive and significant impact on workplace spirituality.

H2: Spiritual leadership has a positive and significant impact on service innovative behavior.

H3: Workplace spirituality has a positive and significant impact on service innovative behavior.

H4: Workplace spirituality will mediate the relationship between spiritual leadership and service innovative behavior.

\section{Methodology}

\subsection{Research data collection procedures}

The study variables were used in past studies and mostly in non-Arabic speaking countries. The authors used back-translation approach with two translators to translate the survey items. Additionally, the survey was tested with five people and few changes were conducted to reduce ambiguities and enhance communication. The data of the study was collected from cities, namely: Amman and Aqaba, and tourist regions, namely: Petra and the Dead Sea. Based on the report from MoTA, Statistics Department (2019), there are 42 five-star hotels and 44 four-star hotels in the mentioned cities and regions with more than 14,000 employees. We contacted the top management of the hotels for permission to conduct the study. Using a convenience sampling technique, data was obtained from employees working in a total of thirty (30) four- and five-star rated hotels who agreed to take part in the current investigation. This sampling technique was utilized to encourage participation due to the long working days and anti-social hours in the industry. We asked the employees to fill out the survey voluntarily, and we also told them they can choose to stop at any time; consequently, we assured them that the responses they gave will be used only for research purposes and will not be disclosed to third parties or the hotel management to mitigate the tendency of social desirability bias and alteration of responses (MacKenzie \& Podsakoff, 2012).

\subsection{Variables and measurements}

Spiritual Leadership has been abstracted as a trichotomic construct with the following subsets: (1) vision - which "describes the organization's journey and why we are taking it; defines who we are and what we do"; (2) hope/faith - which describes "the assurance of things hoped for, the conviction that the organization's vision/ purpose/mission will be fulfilled"; and (3) altruistic love - which describes "a sense of wholeness, harmony, and well-being produced through care, concern, and appreciation for both self and others" (Fry et al., 2005). In this study, the dimensions of spiritual leadership were measured using borrowed 5-items for vision, 5-items for hope/ faith, and 7-items for altruistic love, totaling 17 items (Fry et al., 2005). Sample of items include: "My organization's vision is clear and compelling to me" (vision dimension), "I demonstrate my faith in my organization and its mission by doing everything I can to help us succeed" (hope/ faith dimension), "The leaders in my organization have the courage to stand up for their people" (altruistic love dimension). This scale has been shown to work well in the hospitality context (Afsar et al., 2016) and also fits in with 
the conceptualization in this study.

Workplace Spirituality has been abstracted as a trichotomic construct with the following subsets: (1) meaningful work - at individual level, has to do with employee's perception of joy, energy, and personal meaning in carrying out assigned duties; (2) sense of community - at group level, is interested in employee's sense of connectedness with peers and superiors, supportive atmosphere, and having a shared goal; and (3) alignment of values - at organizational level, is interested in how employee's goals, norms, and values align with those of the hiring organization (Milliman et al., 2003). In this study, the dimensions of workplace spirituality were measured using borrowed 6-items for meaningful work, 7-items for sense of community, and 8-items for alignment of values, totaling 21 items (Milliman et al., 2003). Sample of items include: "I see a connection between work and social good" (meaningful work dimension), "Working cooperatively with others is valued" (sense of community dimension), and "Our organization cares about all its employees" (alignment of values dimension). This scale has been shown to work well in the hospitality context (Milliman et al., 2018) and also fits in with the conceptualization in this study.

Service Innovative Behavior was measured with a first-order construct consisting of 6-items adapted from past studies in the hospitality industry (Hu et al., 2009; Scott \& Bruce, 1994). The items were designed to capture employee's inclination to innovative and creative work behaviors. The research measures were docked on a 5-point Likert scale such that strongly disagree was represented by (1) upward to strongly agree represented by (5). Sample of items include: "At work, I seek new service techniques, methods, or techniques." This scale has been shown to work well in the hospitality context (Hu et al., 2009) and also fits in with the conceptualization in this study.

Demographic features of the employees and the hiring hospitality enterprises under investigation were obtained to help provide a general industrial outlook and the representativeness of the sample. Captured information includes employee educational level, age, gender, hotel classification (e.g., four- or five-star), and yearly revenue of the enterprises. A complete list of the scale items alongside descriptive statistics is presented in the Appendix section.

\section{Results}

\subsection{Participant's profile}

Out of the 1,000 questionnaires distributed, in total, 867 complete answers were retrieved. To compare and comprehend the profile of the research participants, we ran frequency analysis in SPSS software, and the demographic characteristics of the respondents is presented in Table 1. Briefly, information about participating employees' educational level, age groups, gender, type of hiring organization (four- or five-star hotel), and monthly income level. Although a number of hotels did not take part in the study, population ecology theory argues that hotels operating in a common marketplace begin to resemble one another over time. The resemblance is associated with the demographics and/or classification of organizational species (Hannan $\&$ Freeman, 1977). Such that the hotels operating in a common marketplace tend to have employees with similar demographical features, such as education, age, income, etc.

Table 1: Hotel classification according to employee numbers

\begin{tabular}{|l|l|l|l|l|l|l|}
\hline Hotel type & 1-stars & 2-stars & 3-stars & 4-stars & 5-stars & Total \\
\hline Number of employees & 343 & 787 & 1,880 & 3,127 & 10,643 & 16,780 \\
\hline Source (MOTA, 2019), & & & & & & \\
\hline
\end{tabular}

According to the Ministry of Tourism and Antiquities (MOTA), there are approximately 13,770 employees working in five- and four-star hotels out of the entire 16,780 employees in the industry (MOTA, 2019), suggesting that $82 \%$ of the employees in the industry are working in four and five-star hotels (See Table 1 for details). Consequently, in comparison to the hospitality industrial reality, the industry's actual employees' structure and distributions are reflected in the study demographic makeup. Building on the breakdown in Table 2, we concluded that the obtained sample appears to be representable.

\subsection{Measurement model}

This research expended a structural equation modeling technique by drawing on the partial least squares (PLS-SEM) algorithm. The main aspiration of PLS-SEM algorithms and techniques are to maximize the explained variance in the response variable and also to diminish the presence of estimation errors in the response variable (Khaddam et al., 2021; Mert et al., 2021). PLS-SEM operates on composite-grounds and is causal-predictive in terms of estimations (Hair et al., 2019; Yakubu et al., 
2020). PLS-SEM is superior especially when addressing models with multiple direct, indirect, and moderating associations. These features make PLS-SEM superior over the traditional covariance-based SEM. Research variables spiritual leadership and workplace spirituality are operationalized as higher-order constructs. According to Sarstedt et al. (2016), the two-stage approach is useful when a research model has a combination of first-order (e.g., service innovative behavior) and second-order constructs (e.g., spiritual leadership and workplace spirituality) in terms of normalizing the relationships. Specifically, the two-stage approach shows a "better parameter recovery of paths pointing (1) from exogenous constructs to the higher-order construct, and (2) from the higher-order construct to an endogenous construct in the path model" (Sarstedt et al., 2019, p. 199). Following expert recommendations (Sarstedt et al., 2016; 2019), we employed the two-stage approach where the latent scores of the first-order constructs (vision, hope/faith, and altruistic love) were calculated and utilized as indicators for the second-order construct (spiritual leadership). The same approach was applied to workplace spirituality first-order constructs (meaningful work, sense of community, and alignment of values). Although, model fit indices are not necessary in PLS-SEM analysis, we perused the results, which all appear to be sufficient, suggesting a fit between the data

\section{Table 2: Demographic breakdown}

\begin{tabular}{|c|c|c|}
\hline Educational Level & Frequency & Percentage \\
\hline High school & 399 & $46.0 \%$ \\
\hline Diploma & 162 & $18.7 \%$ \\
\hline Bachelor's degree & 277 & $31.9 \%$ \\
\hline Graduate degree & 29 & $3.3 \%$ \\
\hline Total & 867 & $100 \%$ \\
\hline \multicolumn{3}{|l|}{ Age } \\
\hline Less than 20 years & 101 & $11.6 \%$ \\
\hline $21-30$ years & 369 & $42.6 \%$ \\
\hline $31-40$ years & 244 & $28.1 \%$ \\
\hline $41-50$ years & 122 & $14.1 \%$ \\
\hline Above 51 years & 31 & $3.6 \%$ \\
\hline Total & 867 & $100 \%$ \\
\hline \multicolumn{3}{|l|}{ Gender } \\
\hline Female & 152 & $17.5 \%$ \\
\hline Male & 715 & $82.5 \%$ \\
\hline Total & 867 & $100 \%$ \\
\hline \multicolumn{3}{|l|}{ Hotel classification } \\
\hline Four stars & 333 & $38.4 \%$ \\
\hline Five stars & 534 & $61.6 \%$ \\
\hline Total & 867 & $100 \%$ \\
\hline \multicolumn{3}{|l|}{ Income } \\
\hline Less than 499 Dinars $^{1}$ & 549 & $63.3 \%$ \\
\hline Between 500 and 999 Dinars & 223 & $25.7 \%$ \\
\hline Between 1,000 and 1,499 Dinars & 61 & $7.0 \%$ \\
\hline Between 1,500 and 1,999 Dinars & 18 & $2.1 \%$ \\
\hline Above 2,000 Dinars & 16 & $1.8 \%$ \\
\hline Total & 867 & $100 \%$ \\
\hline
\end{tabular}

\footnotetext{
${ }^{1}$ Current exchange rate: 1 Dinar equals 1,23 Euro 
and the model. Indicators and their respective values for model fit are reported in Table 3. We therefore expended SmartPLS software version 3 to operationalize the measurement model. In doing so, we perused the values of Cronbach's alpha $(\mathrm{C} \alpha)$, composite reliability (CR), and Rho to establish construct reliability. In Table 3, all the values were above the 0.70 thresholds (Hair et al., 2019;
Henseler et al., 2009). Consequently, we perused the research indicators using each construct's average variance extracted (AVE), each item's standardized factor loadings, and t-values to establish convergent validity. In Tables 3, the AVE values were above the 0.50 threshold; In Tables 4 the factor loadings and t-values were also above the 0.70 and 1.96 thresholds.

Table 3: Reliability of constructs

\begin{tabular}{|c|c|c|c|c|c|}
\hline & Variables & $\mathrm{C} \alpha$ & Rho & CR & AVE \\
\hline 1 & Spiritual leadership & 0.906 & 0.906 & 0.941 & 0.841 \\
\hline 2 & Workplace spirituality & 0.907 & 0.907 & 0.941 & 0.843 \\
\hline 3 & Service innovative behavior & 0.927 & 0.929 & 0.943 & 0.735 \\
\hline
\end{tabular}

Table 4: Factor loadings, $t$ - and p-statistics for the scale items

\begin{tabular}{|c|c|c|c|c|c|}
\hline Measures & Original Sample & Sample Mean & $\begin{array}{l}\text { Standard } \\
\text { Deviation }\end{array}$ & $\begin{array}{l}\text { T-Statistics } \\
\text { (|O/STDEV|) }\end{array}$ & P-Values \\
\hline \multicolumn{6}{|l|}{ Spiritual leadership } \\
\hline Vision & 0.924 & 0.924 & 0.007 & 126.313 & 0.000 \\
\hline Altruistic love & 0.908 & 0.908 & 0.008 & 118.388 & 0.000 \\
\hline Hope/faith & 0.919 & 0.919 & 0.007 & 134.541 & 0.000 \\
\hline \multicolumn{6}{|l|}{ Workplace spirituality } \\
\hline Sense of community & 0.928 & 0.928 & 0.006 & 142.771 & 0.000 \\
\hline Alignment of values & 0.925 & 0.925 & 0.006 & 158.178 & 0.000 \\
\hline Meaningful work & 0.901 & 0.901 & 0.009 & 102.304 & 0.000 \\
\hline \multicolumn{6}{|l|}{$\begin{array}{l}\text { Service innovative } \\
\text { behavior }\end{array}$} \\
\hline SIB item 1 & 0.860 & 0.860 & 0.011 & 81.032 & 0.000 \\
\hline SIB item2 & 0.888 & 0.888 & 0.010 & 87.510 & 0.000 \\
\hline SIB item3 & 0.884 & 0.884 & 0.010 & 87.052 & 0.000 \\
\hline SIB item4 & 0.866 & 0.866 & 0.011 & 76.635 & 0.000 \\
\hline SIB item5 & 0.796 & 0.796 & 0.017 & 46.636 & 0.000 \\
\hline SIB item6 & 0.845 & 0.844 & 0.013 & 63.485 & 0.000 \\
\hline
\end{tabular}

Table 5: Discriminant validity

\begin{tabular}{|l|l|l|l|l|}
\hline & Variables & $\mathbf{1}$ & $\mathbf{2}$ & $\mathbf{3}$ \\
\hline 1 & Spiritual leadership & $\mathbf{0 . 9 1 7}$ & .912 & 0.679 \\
\hline 2 & Workplace spirituality & 0.828 & $\mathbf{0 . 9 1 8}$ & 0.773 \\
\hline 3 & Service innovative behavior & 0.623 & 0.709 & $\mathbf{0 . 8 5 7}$ \\
\hline
\end{tabular}


Finally, we establish discriminant validity by perusing the square root of each construct's AVE based on the Fornell-Larcker Criterion. All the square roots of the AVE values are above any other inter-construct correlations establishing discriminant validity (Fornell \& Larcker, 1981). The Heterotrait-Monotrait Ratio of Correlations (HTMT) appears to be below the 0.90 threshold with one exception (Henseler et al., 2015). Nevertheless, by combining the results from the Fornell-Larcker Criterion and HTMT in Table 5, we conclude that discriminant validity of the constructs has been established.

\subsection{Structural model}

We tested the study hypotheses through a structural model based on a biased-corrected bootstrapping approach that ran with 5,000 sub-samples. The hypotheses were assessed using the traditional beta, $\mathrm{t}-$ and $\mathrm{p}$-values. To evaluate whether a statistically significant effect also has a practical relevance, we perused the f-squared (f2) values, also known as effect size, following expert guidelines (Cohen, 2013) where (large effect $=0.35)$, (moderate effect $=0.15)$, and (small effect $=0.02$ ). The structural model presented in Figure 1 generated four distinct outcomes as follows: First, the results show that spiritual leadership has a significant and positive effect on workplace spirituality ( $\beta=$ $0.828, \rho<0.01)$. This suggests that a $100 \%$ increase in spiritual leadership can result in an $82.8 \%$ increase in the level of workplace spirituality. Furthermore, spiritual lead- ership also explained $68.6 \%$ of the variance in workplace spirituality ( $\mathrm{R}$-squared $=0.686$ ), and effect size is deemed to be very large (f-squared $=2.180$ ). Based on these results, hypothesis 1 received empirical support. Details are available in Table 6.

Second, the results show that spiritual leadership has a significant and positive effect on service innovative behavior $(\beta=0.114, \rho<0.01)$. This suggests that a $100 \%$ increase in spiritual leadership can result in an $11.4 \%$ increase in the level of service innovative behavior. The effect size is deemed to be very small ( $\mathrm{f}$-squared $=0.008$ ). Based on these results, hypothesis 2 received empirical support. Details are available in Table 6.

Third, the results show that workplace spirituality has a significant and positive effect on service innovative behavior $(\beta=0.615, \rho<0.01)$. This suggests that a $100 \%$ increase in workplace spirituality can result in a $61.5 \%$ increase in the level of service innovative behavior. The effect size is deemed to be moderate (f-squared $=0.24$ ). Based on these results, hypothesis 3 received empirical support. Details are available in Table 6.

Fourth, spiritual leadership and workplace spirituality jointly explained $50.7 \%$ of the variance in service innovative behavior $(\mathrm{R}$-squared $=0.507)$. Finally, the mediating role of workplace spirituality on the relationship between spiritual leadership and service innovative behavior holds $(\beta=0.509, \rho<0.01)$. Based on these results, hypothesis 4 received empirical support. Details are available in Table 6.

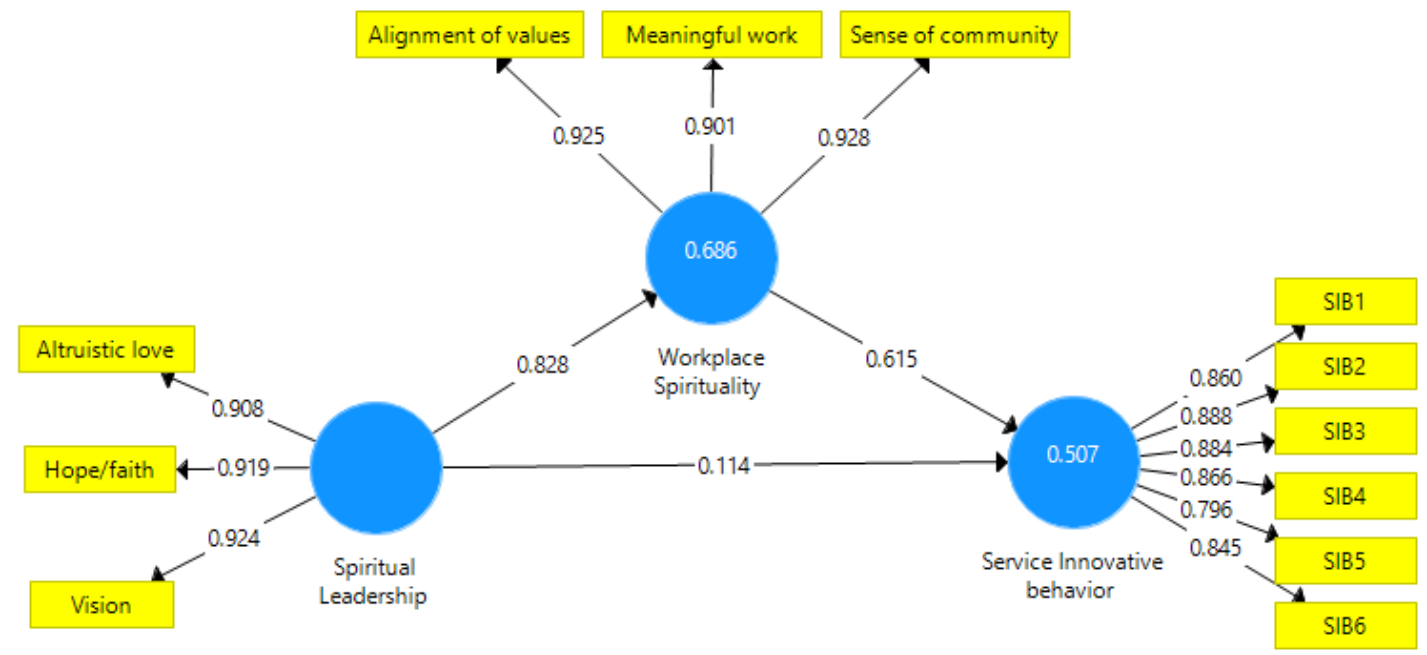

Figure 1: Structural model 
Table 6: Direct and indirect effects

\begin{tabular}{|c|c|c|c|}
\hline \multicolumn{2}{|l|}{ Panels } & \multicolumn{2}{|l|}{ Endogenous variables } \\
\hline \multicolumn{4}{|l|}{ Panel A - Direct effects } \\
\hline Exogeneous variables & & Workplace spirituality & Service innovative behavior \\
\hline Spiritual leadership & & $0.828 * *$ & $0.114^{*}$ \\
\hline Workplace spirituality & & - & $0.615^{*}$ \\
\hline \multicolumn{4}{|c|}{ Panel B - Effect sizes (F-squared) } \\
\hline Spiritual leadership & & 2.180 & 0.008 \\
\hline Workplace spirituality & & NA & 0.241 \\
\hline \multicolumn{4}{|c|}{ Panel C - Specific indirect effect (Mediation) } \\
\hline Exogeneous variables & Mediator variables & & Service innovative behavior \\
\hline Spiritual leadership & Workplace spirituality & - & $0.509 * *$ \\
\hline
\end{tabular}

\section{Discussion}

\subsection{Findings}

Drawing on relational energy theory, we examined the association among spiritual leadership, workplace spirituality, and service innovative behavior. Results show that spiritual leadership increases the level of workplace spirituality, which makes sense as spiritual leaders have a specific desire and focus to energize the connection between the leaders, the organization, and their employees (Afsar et al., 2016). We also show that spiritual leadership and workplace spirituality can enact higher levels of service innovative behavior among employees (Afsar \& Badir, 2017). Employees see spiritual experience as a personal bond to work activities and other entities who are touched by it, which goes beyond self-interest. We extend past work by unveiling the potentials of spiritual leadership to foster service innovative behavior and also show that spiritual work cultures are vital for innovative outcomes. In other words, workplace spirituality mediates the relationship between spiritual leadership and service innovative behavior.

Employees are mostly under stress, and sometimes even alienated from their organizations. Spiritual leaderships create a work atmosphere and culture of support, meaningful work life, community of support and achieving goals, which may reduce employees' fear and insecurity; these, we show, can enhance their confidence and sense of sharing that could further result in innovative ideas and ways of dealing with business problems. Although, spirituality in the Middle East has religious roots (Abu-El-Noor \& Abu-El-Noor, 2019), the mainstream attributes such as connection, peace, transcendence, and seeking meaning and purpose are like those of the Western context (Weath- ers, 2018). There is a fine line between spirituality and religion in the Jordanian society because individuals live in a way that religious beliefs are reflected in all aspects of their lives, including work life.

In lieu of this, this study denotes that spiritual beliefs and practices are excellent sources of support, comfort, and coping mechanisms that can be built upon to create positive a work atmosphere for innovative activities in the Jordanian tourism and hospitality context. Past research noted that in Muslim perspectives, spirituality practices were mainly derived from the Holy Quran and the Hadiths (Cruz et al., 2017). Given that the Jordanian population is predominantly from the Sunni sect, the applicability of the current findings in other Arabian or Middle Eastern contexts is contingent upon the Islamic sect. In sum, the findings are in congruence with existing assertions in the literature on the effects of spiritual leadership and workplace spirituality on work outcomes such as performance (Duchon \& Plowman, 2005; Yang et al., 2019), innovativeness (Afsar et al., 2016; Ghaedi et al., 2020), positive attitudes, and prosocial behaviors (Rezapouraghdam et al., 2018; Wierzbicki \& Zawadzka, 2016). Although four- and five-star hotels employs a large portion of approximately $82 \%$ of the hotel industry workforce in Jordan (MOTA, 2019). It is also important to caution readers about the generalizability and interpretations of the current findings. The fact that the study sample was drawn from four- and five-star hotels limits our ability to generalize and draw inference on the applicability of the findings in other hotel settings such as one-, two- and three-star hotels that are mainly family owned and managed. 


\subsection{Theoretical and practical implications}

The results of the current study delineate that spiritual leadership impacts and increases the level of workplace spirituality and service innovative behavior. Consequently, workplace spirituality increases the level of service innovative behavior and mediates the relationship between spiritual leadership and service innovative behavior. This paper's theoretical contributions and originality does not only lie in uncovering how and when spiritual leadership influences service innovative behavior, but also on the mediating mechanisms of workplace spirituality. Understanding how spiritual leadership and workplace spirituality predict service innovative behavior theoretically enriches the hospitality management literature. Logically, this is a viable way to understand a spectrum of leader actions and environmental forces that are productive and beneficial. Afsar et al. (2016) and Milliman et al. (2018) previously suggested more empirical evidence on these interdependences. This paper addresses this research call by showing the mediating role of workplace spirituality on the relationship between spiritual leadership and service innovative behavior in the tourism and hospitality context. The current study also extends the scope by drawing on relational energy as a theoretical framework. By taking this lens, this work unveils the black box between spiritual leadership and service innovative behavior. Specifically, spiritual leaders are social innovators of good and positive energy that reinforces a sense of community membership, transcendence, meaning, and shared values among employees, which reflected and/or reciprocated in their work behavior in form increased service innovative behavior.

Besides theoretical contributions, the findings in this paper have a few industrial implications. We recommend that hospitality enterprises in Jordan should take spirituality into consideration when selecting and training supervisors or unit chiefs. In other words, HR professionals should promote spirituality to ensure that potential managers or supervisors fully recognize the benefits of spirituality leadership and its outcomes. For instance, organizing social activities and counseling sessions to help both leaders and employees build a positive understanding of workplace spirituality. Hospitality enterprises often place emphasis on technical training and compensations as predictors of innovation, this work suggests that hospitality enterprises in Jordan should include the soft side of management, in terms of creating a workplace culture with spirituality and placing individuals with spiritual awareness in supervisory positions. The findings assert that having spiritual leaders and working in a spiritual environment where individuals are cared for, loved, appreciated, and supported by leaders and co-workers can encourage employees to carry out service innovative behavior and/or activities.

\subsection{Limitations and future research}

This research has several clampdowns that should be mentioned, starting with the design; the cross-sectional design may affect causational claims. Although, the study utilized a large sample size, the exclusion of one-, two- and three-star hotels reduce the generalizability of the findings in the Jordanian hotel industry. The observed variables data were obtained through self-assessment and as such may be susceptible to social desirability bias. Future works are encouraged to use multi-source or secondary data sources and longitudinal design to mitigate these problems. Consequently, the usage of non-probability sampling technique: convenience has the tendency to omit certain species in the population, thus, upcoming works are encouraged to utilize random sampling techniques for a more representable sample. Also, this paper did not consider the role of mindfulness, justice, organizational, and co-worker support on the scrutinized associations. Spiritual leadership and workplace spirituality have been shown to play a moderating role on the association between antecedents of burnout; what remains unclear is the role spiritual leadership and workplace spirituality play in the link between antecedents and boreout, the opposite of burnout. Another fruitful research avenue could be knowledge-related outcomes, such as individual sharing, hiding, sabotage, and the like. Finally, the model could be tested in other industries and countries as spirituality varies across countries and cultures.

\subsection{Conclusion}

The present research provides a new direction for underexplored spirituality and service innovative outcomes. Building on the relational energy theoretical framework, this study explores the influence of spiritual leadership on workplace spirituality and service innovative behavior, and the mediating role of workplace spirituality on the relationship between spiritual leadership and service innovative behavior. We contribute to literature theoretically and empirically by proving the presence of the path between spirituality and innovative work outcomes in a non-Western context. We found that spiritual leadership enhances workplace spirituality and service innovative behavior; workplace spirituality enhances service innovative behavior and also mediated the relationship between spiritual leadership and service innovative behavior.

\section{Literature}

Abu-El-Noor, M.K., \& Abu-El-Noor, N.I. (2019). Spirituality and Spiritual Care in the Arab World. In: Laher I. (eds) Handbook of Healthcare in the Arab World. Springer, Cham. https://doi.org/10.1007/978-3-319- 
74365-3 68-1

Afsar, B., Badir, Y., \& Kiani, U. S. (2016). Linking spiritual leadership and employee pro- environmental behavior: The influence of workplace spirituality, intrinsic motivation, and environmental passion. Journal of Environmental Psychology, 45, 79-88. https://doi. org/10.1016/j.jenvp.2015.11.011

Afsar, B., \& Badir, Y. (2017). Workplace spirituality, perceived organizational support and innovative work behavior: The mediating effects of person-organization fit. Journal of Workplace Learning, 29(2), 95-109. https://doi.org/10.1108/JWL-11-2015-0086

Abubakar, A. M. (2018). Linking work-family interference, workplace incivility, gender and psychological distress. Journal of Management Development, 37(3), 226-242. https://doi.org/10.1108/JMD-06-2017-0207

Borgatti, S. P., \& Cross, R. (2003). A relational view of information seeking and learning in social networks. Management Science, 49(4), 432-445. https://doi. org $/ 10.1287 / \mathrm{mnsc} .49 .4 .432 .14428$

Duchon, D., \& Plowman, D. A. (2005). Nurturing the spirit at work: Impact on work unit performance. The Leadership Quarterly, 16(5), 807-833. https://doi. org/10.1016/j.leaqua.2005.07.008

Cohen, J. (2013). Statistical power analysis for the behavioral sciences. Academic press New York

Cozzarin, B. P. (2017). Impact of organizational innovation on product and process innovation. Economics of Innovation and New Technology, 26(5), 405-417. https://doi.org/10.1080/10438599.2016.1204779

Cruz, J. P., Alshammari, F., Alotaibi, K. A., \& Colet, P. C. (2017). Spirituality and spiritual care perspectives among baccalaureate nursing students in Saudi Arabia: A cross-sectional study. Nurse Education Today, 49, 156-162. https://doi.org/10.1016/j.nedt.2016.11.027

Fornell, C., \& Larcker, D. F. (1981). Evaluating structural equation models with unobservable variables and measurement error. Journal of Marketing Research, 18(1), 39-50. https://doi.org/10.2307/3151312

Fry, L. W., \& Slocum, J. W. (2008). Maximizing the triple bottom line through spiritual leadership. Organizational Dynamics, 37(1), 86-96. https://doi.org/10.1016/j. orgdyn.2007.11.004

Fry, L. W., Vitucci, S., \& Cedillo, M. (2005). Spiritual leadership and army transformation: Theory, measurement, and establishing a baseline. The Leadership Quarterly, 16(5), 835-862. http://dx.doi.org/10.1016/j. leaqua.2005.07.012

Ghaedi, A., Ozturen, A., \& Safshekan, S. (2020). Workplace mistreatment and spiritual leadership: new cure for ancient curse. Current Issues in Tourism, 1-14. https://doi.org/10.1080/13683500.2020.1719988

Giacalone, R. A., \& Jurkiewicz, C. L. (2003). Right from wrong: The influence of spirituality on perceptions of unethical business activities. Jour- nal of Business Ethics, 46(1), 85-97. https://doi. org/10.1023/A:1024767511458

Gotsis, G., \& Grimani, K. (2017). The role of spiritual leadership in fostering inclusive workplaces. Personnel Review, 46(5), 908-935. https://doi.org/10.1108/ PR-11-2015-0286

Hair, J. F., Risher, J. J., Sarstedt, M., \& Ringle, C. M. (2019). When to use and how to report the results of PLS-SEM. European Business Review, 31(1), 2-24. https://doi.org/10.1108/EBR-11-2018-0203

Hannan, M. T., \& Freeman, J. (1977). The population ecology of organizations. American Journal of Sociology, 82(5), 929. https://www.jstor.org/stable/2777807

Helmy, I., Adawiyah, W. R., \& Setyawati, H. A. (2020). Fostering Frontline Employees' Innovative Service Behavior: The Role of Workplace Friendship and Knowledge Sharing Process. Organizacija, 53(3), 185196. https://doi.org/10.2478/orga-2020-0012

Henseler, J., Ringle, C. M., \& Sinkovics, R. R. (2009). The use of partial least squares path modeling in international marketing, Sinkovics, R.R. and Ghauri, P.N. (Ed.) New Challenges to International Marketing (Advances in International Marketing, Vol. 20), Emerald Group Publishing Limited, Bingley, pp. 277-319.

https://doi.org/10.1108/S14747979(2009)0000020014

Henseler, J., Ringle, C. M., and Sarstedt, M. (2015). A New Criterion for Assessing Discriminant Validity in Variance-based Structural Equation Modeling. Journal of the Academy of Marketing Science, 43(1), 115-135. https://doi.org/10.1007/s11747-014-0403-8

Houghton, J. D., Neck, C. P., \& Krishnakumar, S. (2016). The what, why, and how of spirituality in the workplace revisited: A 14-year update and extension. Journal of Management, Spirituality \& Religion, 13(3), 177-205. https://doi.org/10.1080/14766086.2016.118 5292

Hu, M. L. M., Horng, J. S., \& Sun, Y. H. C. (2009). Hospitality teams: knowledge sharing and service innovation performance. Tourism Management, 30(1), 41-50. https://doi.org/10.1016/j.tourman.2008.04.009

Jurkiewicz, C.L., \& Giacalone, R.A. (2004) A Values Framework for Measuring the Impact of Workplace Spirituality on Organizational Performance. Journal of Business Ethics, 49, 129-142. https://doi. org/10.1023/B:BUSI.0000015843.22195.b9

Kaya, B., Abubakar, A. M., Behravesh, E., Yildiz, H., \& Mert, I. S. (2020). Antecedents of innovative performance: Findings from PLS-SEM and fuzzy sets (fsQCA). Journal of Business Research, 114, 278-289. https://doi.org/10.1016/j.jbusres.2020.04.016

Khaddam, A. A., Alzghoul, A., Abusweilem, M. A., \& Abousweilem, F. (2021). Business intelligence and firm performance: a moderated-mediated model. The Service Industries Journal, 1-17. https://doi.org/10.10 
80/02642069.2021.1969367

Krishnakumar, S., Houghton, J. D., Neck, C. P., \& Ellison, C. N. (2015). The "good" and the "bad" of spiritual leadership. Journal of Management, Spirituality \& Religion, 12(1), 17-37. https://doi.org/10.1080/14766086 .2014 .886518

Likoum, S. W. B., Shamout, M. D., Harazneh, I., \& Abubakar, A. M. (2020). Market-sensing capability, innovativeness, brand management systems, market dynamism, competitive intensity, and performance: an integrative review. Journal of the Knowledge Economy, 11(2), 593-613. https://doi.org/10.1007/s13132018-0561-x

MacKenzie, S. B., \& Podsakoff, P. M. (2012). Common method bias in marketing: Causes, mechanisms, and procedural remedies. Journal of Retailing, 88(4), 542555. https://doi.org/10.1016/j.jretai.2012.08.001

Mert, İ. S., Sen, C., \& Alzghoul, A. (2021). Organizational justice, life satisfaction, and happiness: the mediating role of workplace social courage. Kybernetes, Vol. ahead-of-print No. ahead-of-print. https://doi.or$\mathrm{g} / 10.1108 / \mathrm{K}-02-2021-0116$

Milliman, J., Czaplewski, A. J., \& Ferguson, J. (2003). Workplace spirituality and employee work attitudes: An exploratory empirical assessment. Journal of Organizational Change Management, 16(4), 426-447. https://doi.org/10.1108/09534810310484172

Milliman, J., McDaniel, D. M. (2011). Energy at work: A multinational, cross-situational investigation of relational energy. University of California, Irvine.

Milliman, J., Gatling, A., \& Kim, J. S. (2018). The effect of workplace spirituality on hospitality employee engagement, intention to stay, and service delivery. Journal of Hospitality and Tourism Management, 35, 56-65. http://dx.doi.org/10.1016/j.jhtm.2018.03.002

Milliman, J., Czaplewski, A.J., \& Ferguson, J. (2003). Workplace spirituality and employee work attitudes: An exploratory empirical assessment. Journal of Organizational Change Management, 16 (4), 426-447. https://doi.org/10.1108/09534810310484172

MOTA (2019). Statistical Bulletins available on The Official Website of Ministry of Tourism and Antiquities for 2019. Available online at: http://www.mota.gov.jo

Oh, J., \& Wang, J. (2020). Spiritual leadership: Current status and Agenda for future research and practice. Journal of Management, Spirituality \& Religion, 17(3), 223-248. https://doi.org/10.1080/14766086.2020.172 8568

Owens, B. P., Baker, W. E., Sumpter, D. M., \& Cameron, K. S. (2016). Relational energy at work. Implications for job engagement and job performance. Journal of Applied Psychology, 101(1), 35-49. http://doi. org/10.1037/ap10000032

Rahman, M.S., Zaman, M.H., Hossain, M.A., Mannan, M., \& Hassan, H. (2019). Mediating effect of employee's commitment on workplace spirituality and executive's sales performance: An empirical investigation. Journal of Islamic Marketing, 10(4),1057-1073. https://doi. org/10.1108/JIMA-02-2018-0024

Rezapouraghdam, H., Alipour, H., \& Darvishmotevali, M. (2018). Employee workplace spirituality and pro-environmental behavior in the hotel industry. Journal of Sustainable Tourism, 26(5), 740-758. https://doi.org/1 0.1080/09669582.2017.1409229

Sarstedt, M., Hair, J. F., Ringle, C. M., Thiele, K. O., \& Gudergan, S. P. (2016). Estimation issues with PLS and CBSEM: Where the bias lies!. Journal of Business Research, 69(10), 3998-4010. https://doi.org/10.1016/j. jbusres.2016.06.007

Sarstedt, M., Hair Jr, J. F., Cheah, J. H., Becker, J. M., \& Ringle, C. M. (2019). How to specify, estimate, and validate higher-order constructs in PLS-SEM. Australasian Marketing Journal (AMJ), 27(3), 197-211. https://doi.org/10.1016/j.ausmj.2019.05.003

Scott, S. G., \& Bruce. (1994). Determinants of innovative behavior: a path model of individual innovation in the workplace. The Academy of Management Journal, 37(3), 580-607. https://doi.org/10.2307/256701

Shih, H. A., \& Susanto, E. (2017). Perceived identifiability, shared responsibility and innovative work behavior. The International Journal of Human Resource Management, 28(22), 3109-3127. https://doi.org/10.10 80/09585192.2016.1143860

Tabor, W., Madison, K., Marler, L.E., \& Kellermanns, F. W. (2019). The effects of spiritual leadership in family firms: A conservation of resources perspective. Journal of Business Ethics, 163, 729-743. https://doi. org/10.1007/s10551-019-04379-2

Yang, F., Liu, J., Wang, Z., \& Zhang, Y. (2019). Feeling energized: a multilevel model of spiritual leadership, leader integrity, relational energy, and job performance. Journal of Business Ethics, 158(4), 983-997. https://doi.org/10.1007/s10551-017-3713-1

Yakubu, M. N., Dasuki, S. I., Abubakar, A. M., \& Kah, M. M. (2020). Determinants of learning management systems adoption in Nigeria: A hybrid SEM and artificial neural network approach. Education and Information Technologies, 25, 3515-3539. https://doi.org/10.1007/ s10639-020-10110-w

Wang, J., Zhang, Z., \& Jia, M. (2017). Understanding how leader humility enhances employee creativity: The roles of perspective taking and cognitive reappraisal. The Journal of Applied Behavioral Science, 53(1), 5-31. https://doi.org/10.1177/0021886316678907

Weathers, E. (2018). Spirituality and health: A Middle Eastern perspective. Religions, 9(2), 33. https://doi. org/10.3390/rel9020033

Wierzbicki, J., \& Zawadzka, A. M. (2016). The effects of the activation of money and credit card vs. that of activation of spirituality-Which one prompts pro-social behaviors? Current Psychology, 35(3), 344-353. https://doi.org/10.1007/s12144-014-9299-1 
Hebah Suliman ALFARAJAT is a PhD candidate at Faculty of Business and Economics, Girne American University, Girne, Cyprus. Her research interests span into human resource management domain, leadership, organizational behavior and workplace spirituality.

Okechukwu Lawrence EMEAGWALI, PhD, is Associate Professor of Strategic Management at the Girne American University, Cyprus. He is also the head of the Department of Business Management and the director of the Center for Management Research (CMR), housed in the Faculty of Business and Economics. He lectures, speaks, advises and researches on topics bordering around business strategy and general business management. His research interests lie within the strategic management field, particularly the action-based competitive interaction sub-stream of the competitive dynamics research area. He links his research, practice and teaching experiences to provide practical recommendations and unique insights to the various academic and corporate stakeholder groups he is currently involved with. 


\section{Appendix I: Measurement Items}

\begin{tabular}{|c|c|c|}
\hline Spiritual Leadership & Mean & SD \\
\hline \multicolumn{3}{|l|}{ Vision } \\
\hline 1. "I understand and am committed to my organization's vision". & 3.84 & 1.14 \\
\hline 2. "My workgroup has a vision statement that brings out the best in me". & 3.96 & 1.06 \\
\hline 3. "My organization's vision inspires my best performance". & 3.84 & 1.09 \\
\hline 4. "I have faith in my organization's vision for its employees". & 3.83 & 1.06 \\
\hline 5. "My organization's vision is clear and compelling to me". & 3.88 & 1.10 \\
\hline \multicolumn{3}{|l|}{ Hope/faith } \\
\hline $\begin{array}{l}\text { 1. "I have faith in my organization, and I am willing to do whatever it takes to ensure that it } \\
\text { accomplishes its mission" }\end{array}$ & 3.96 & 1.09 \\
\hline $\begin{array}{l}\text { 2. "I persevere and exert extra effort to help my organization succeed because I have faith in } \\
\text { what it stands for" }\end{array}$ & 4.02 & 1.03 \\
\hline 3. "I always do my best in my work because I have faith in my organization and its leaders" & 4.00 & 1.02 \\
\hline $\begin{array}{l}\text { 4. "I set challenging goals for my work because I have faith in my organization and want us to } \\
\text { succeed" }\end{array}$ & 3.67 & 1.18 \\
\hline $\begin{array}{l}\text { 5. "I demonstrate my faith in my organization and its mission by doing everything I can to help } \\
\text { us succeed" }\end{array}$ & 4.03 & 1.02 \\
\hline \multicolumn{3}{|l|}{ Altruistic love } \\
\hline 1. "My organization really cares about its people" & 3.67 & 1.18 \\
\hline $\begin{array}{l}\text { 2. "My organization is kind \& considerate toward its workers, and when they are suffering, } \\
\text { wants to do something about it" }\end{array}$ & 3.73 & 1.11 \\
\hline 3. "The leaders in my organization walk the walk as well as talk the talk" & 3.74 & 1.15 \\
\hline 4. "My organization is trustworthy and loyal to its employees" & 3.66 & 1.19 \\
\hline 5. "My organization does not punish honest mistakes" & 3.62 & 1.18 \\
\hline 6. "The leaders in my organization are honest and without false pride" & 3.76 & 1.10 \\
\hline 7. "The leaders in my organization have the courage to stand up for their people" & 3.69 & 1.18 \\
\hline \multicolumn{3}{|l|}{ Workplace Spirituality } \\
\hline \multicolumn{3}{|l|}{ Meaningful work } \\
\hline 1. "I experience joy in work" & 3.82 & 1.14 \\
\hline 2. "Spirit is energized by work" & 3.85 & 1.03 \\
\hline 3. "Work is connected to what I think is important in life" & 3.90 & 1.02 \\
\hline 4. "I look forward to coming to work" & 3.81 & 1.05 \\
\hline 5. "I see a connection between work and social good" & 3.83 & 1.03 \\
\hline 6. "I understand what gives my work personal meaning" & 4.00 & 0.96 \\
\hline \multicolumn{3}{|l|}{ Sense of community } \\
\hline 1. "Working cooperatively with others is valued" & 4.04 & 1.11 \\
\hline 2. "I feel part of a community" & 4.05 & 1.01 \\
\hline 3. "I believe people support each other" & 3.80 & 1.06 \\
\hline 4. "I feel free to express opinions" & 3.80 & 1.10 \\
\hline 5. "I think employees are linked with a common purpose" & 3.74 & 1.07 \\
\hline 6. "I believe employees genuinely care about each other" & 3.70 & 1.09 \\
\hline
\end{tabular}




\section{Appendix I: Measurement Items (continues)}

\begin{tabular}{|l|l|l|}
\hline 7. "I feel there is a sense of being a part of a family" & 3.75 & 1.12 \\
\hline Alignment of values & & \\
\hline 1. "I feel positive about the values of the organization" & 3.81 & 1.12 \\
\hline 2. "Our organization is concerned about the poor" & 3.64 & 1.15 \\
\hline 3. "Our organization cares about all its employees" & 3.60 & 1.16 \\
\hline 4. "Our organization has a conscience" & 3.78 & 1.08 \\
\hline 5. "I feel connected with the organization's goals" & 3.76 & 1.04 \\
\hline 6. "Our organization is concerned about health of employees" & 3.77 & 1.08 \\
\hline 7. "I feel connected with the mission of the organization" & 3.81 & 1.01 \\
\hline 8. "Our organization cares about whether my spirit is energized" & 3.75 & 1.09 \\
\hline & & \\
\hline 1. "At work, I come up with innovative and creative notions" & 3.87 & 1.04 \\
\hline 2. "At work, I try to propose my own creative ideas and convince others" & 3.92 & 0.96 \\
\hline 3. "At work, I seek new service techniques, methods, or techniques" & 3.97 & 0.93 \\
\hline 4. "At work, I provide a suitable plan for developing new ideas" & 3.93 & 0.96 \\
\hline 5. "At work, I try to secure the funding and resources needed to implement innovations" & 3.90 & 0.98 \\
\hline 6. "Overall, I consider myself a creative member of my team" & 4.01 & 1.01 \\
\hline
\end{tabular}

